\title{
Enfermedad por arañazo de gato como causa de fiebre de origen desconocido
}

\author{
Salomé Santarcángelo, Rubén Sosa, Patricia Dondoglio, Lidia E. Valle y Daniel Navacchia
}

\section{Cat scratch disease as fever of unknown origin}

The cat scratch disease is a relatively rare disease caused by Bartonella henselae. Only a small proportion of the cases that described extranodal involvement occurs. We report a 11 year old male patient with persistent fever, liver and osteoarticular involvement with a predominance of dorsolumbar spine. Evolution was satisfactory with complete clinical and imaging evidenced recovery in several months of monitoring. Case was analyzed considering EAG published literature, emphasizing the need to include this condition in the differential diagnoses in patients with bone involvement suggestive of systemic disease.

Key words: Scratch cat disease, fever of unknown origin.

Palabras clave: Enfermedad por arañazo de gato, síndrome febril prolongado.

\section{Introducción}

$\mathrm{L}$ a enfermedad por arañazo de gato es una infección usualmente benigna y autolimitada, producida por un bacilo gramnegativo pleomórfico, Bartonella henselae, causante además de la angiomatosis bacilar y la peliosis hepática.

El gato doméstico es el mayor reservorio de $B$. henselae, así como también el principal vector para la transmisión a los humanos. Es más común en los cachorros que son seropositivos en $75 \%$. Existen reportes anecdóticos de transmisión por otros animales como perros y monos.

Entre los 7 y 50 días posteriores al contacto con gatos, espinas de rosas o cactus infectados, se observa una lesión papulosa o pustulosa en el sitio del rasguño. Esta lesión de inoculación se acompaña de una linfo-adenopatía regional, caracterizada por un aumento de volumen ganglionar, sensible, rojo, indurado y, en algunas oportunidades, con supuración y/o fistulización.

En forma ocasional puede asociarse a compromiso del estado general con fiebre prolongada, cefalea, anorexia, fatiga y linfo-adenopatías, generalmente axilares y/o submandibulares y compromiso hepato-esplénico.

En las formas comunes la evolución y el pronóstico son excelentes, pudiendo curar espontáneamente en dos a tres meses. Sin embargo, existen formas atípicas en $10 \%$ y graves en $2 \%$ de los casos $^{1}$.

Se presenta el caso clínico de un niño de 11 años, de sexo masculino, con un síndrome febril prolongado, con compromiso sistémico hepato-esplénico y óseo múltiple con predominio de la columna vertebral dorsolumbar.

\section{Caso clínico}

Escolar de 11 años, de sexo masculino, procedente de la provincia de Buenos Aires. Ingresó a nuestro hospital por un cuadro de fiebre prolongada de un mes de evolución, decaimiento, anorexia, agregándose en los días previos a la consulta un dolor articular en la región dorsal y lumbosacra, dolor muscular y temblor de las extremidades inferiores. Además refería sudor nocturno y una pérdida de peso de tres kilogramos (peso $32 \mathrm{~kg}$, percentil 25). No se rescataron antecedentes epidemiológicos significativos ni enfermedades previas. El examen físico reveló un niño febril $39^{\circ} \mathrm{C}$, quejumbroso, con dolor dorso-lumbar que dificultaba la pedestación y la marcha, rigidez de columna vertebral dorso-lumbo-sacra con envaramiento y temblor intencional en la extremidad inferior izquierda. Presentaba dolor y limitación a la movilidad pasiva coxo-femoral bilateral. Los reflejos osteotendinosos estaban presentes y con trofismo muscular conservado. Presentaba una adenopatía axilar izquierda de 1 x $2 \mathrm{~cm}$, móvil. El examen cardiorespiratorio era normal. El abdomen estaba distendido, depresible y sin visceromegalias a la palpación.

Se realizaron exámenes de laboratorio: hemograma: $\mathrm{Hb} 12,1 \mathrm{~g} / \mathrm{dl}$, Hto $36 \%$, leucocitos $8.600 / \mathrm{mm}^{3}(63 \%$ neutrófilos), plaquetas $425.000 / \mathrm{mm}^{3}$, VHS: $91 \mathrm{~mm} 1^{\circ} \mathrm{h}$. Perfil proteico: proteínas totales: 8,2 g/dl, albúmina 3,7 g/ $\mathrm{dl}$, alfa 1-globulinas $0,3 \mathrm{~g} / \mathrm{dl}$, alfa 2-globulinas $1,3 \mathrm{~g} / \mathrm{dl}$. Inmunoglobulinas totales $2,1 \mathrm{~g} / \mathrm{dl}, \mathrm{IgA} 446 \mathrm{mg} / \mathrm{dl}, \mathrm{Ig} \mathrm{M}$ $265 \mathrm{mg} / \mathrm{dl}$, IgE $89 \mathrm{mg} / \mathrm{dl}$, IgG $2.050 \mathrm{mg} / \mathrm{dl}$. Perfil hepático: bilirrubina total: $0,5 \mathrm{mg} / \mathrm{dl}$, bilirrubina directa: $0,2 \mathrm{mg} / \mathrm{dl}$, GOT: $22 \mathrm{U} / \mathrm{L}, \mathrm{GPT}: 20 \mathrm{U} / \mathrm{L}$, fosfatasas alcalinas: $603 \mathrm{U} / \mathrm{L}$.
Hospital General de Niños Pedro de Elizalde, Buenos Aires, Argentina.

Departamento de Pediatría. División Clínica Pediátrica (SS). Unidad de Enfermedades Infecciosas (RS, PD). Unidad de Dermatología Pediátrica (LEV) (hasta año 2010). Departamento de Servicios Centrales Diagnóstico y Tratamiento (DN).

Recibido: 18 de diciembre de 2012 Aceptado: 30 de mayo de 2013

Correspondencia a: Salomé Santarcángelo. scsantarcangelo@gmail.com 
Figura 1. TAC de columna vertebral dorsolumbar. Lesión de tipo lítico en una vértebra dorsal.

Figura 2. TAC abdominal. Se observan imágenes hipodensas en el hígado.

Figura 3. TAC abdominal. Se observan imágenes hipodensas en el bazo.
Este estudio inicial, con alteración de los reactantes de fase aguda, orientó a la presencia de un proceso infeccioso como causa del síndrome febril prolongado, de etiología bacteriana, tuberculosa o viral.
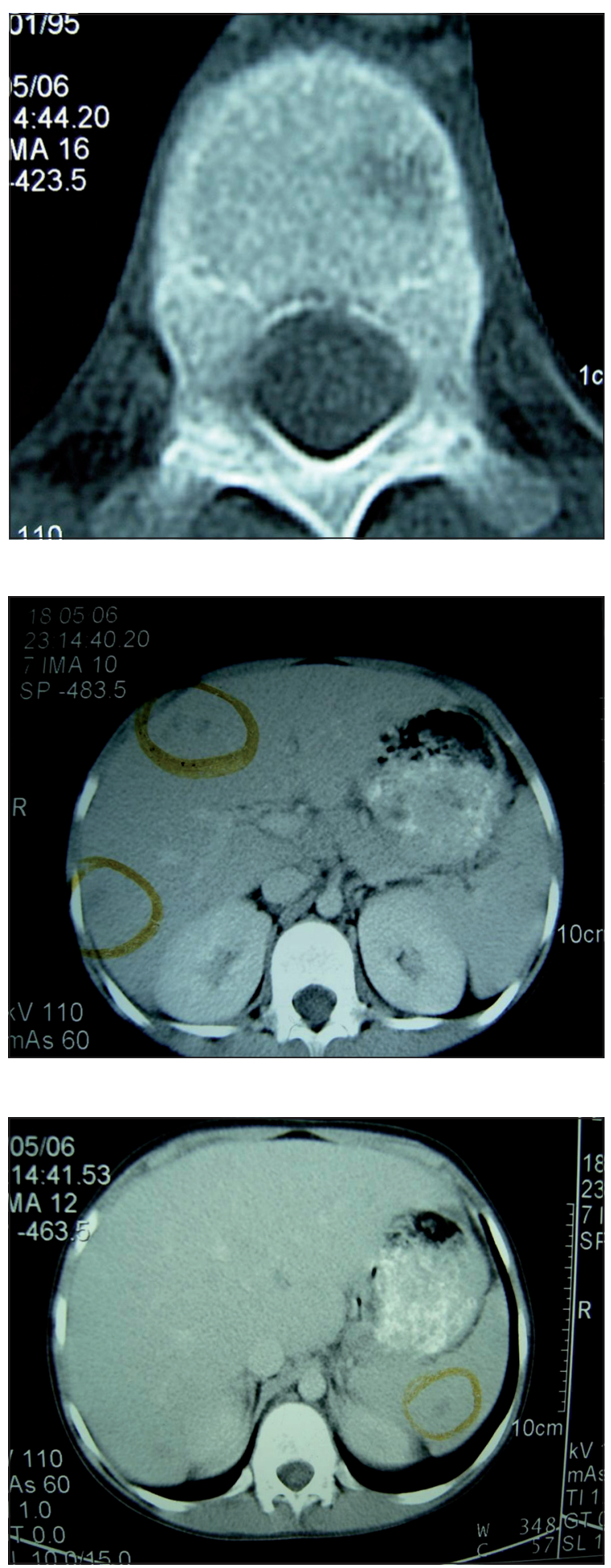

Se realizó un estudio inicial de imágenes con búsqueda de focos infecciosos profundos: la ecocardiografía y fondo de ojo fueron normales. La ecografía abdominal mostró una leve hepatomegalia de estructura heterogénea, con dos imágenes hipoecogénicas de $17 \mathrm{~mm}$ y $15 \mathrm{~mm}$, mientras que el bazo presentaba múltiples imágenes hipoecogénicas. La radiografía de ambas caderas no mostró alteraciones óseas y la ecografía de ambas articulaciones no evidenció la presencia de colección intra-articular.

En relación a la investigación etiológica, los hemocultivos no tuvieron desarrollo bacteriano, los exámenes directos de esputo para bacilos ácido-alcohol resistentes fueron negativos y la reacción PPD fue negativa. Las serologías ASO, VDRL, ELISA para VIH, Widal, Huddleson, CMV, Epstein Barr, hepatitis A, B y toxocara fueron no reactivas.

La brucelosis como causa de síndrome febril prolongado, si bien tiene una presentación pleomórfica, en este caso las series hematológicas no estaban comprometidas, ni había antecedentes epidemiológicos orientadores.

El examen de médula ósea fue normal, lo que permitió descartar una enfermedad linfoproliferativa maligna.

$\mathrm{La}$ inmunofluorescencia indirecta (IFI) $\mathrm{IgG}$ para $B$. henselae fue informada como positiva en $1 / 64$, con un punto de corte de 1/64. (Laboratorio de referencia: Instituto Nacional de Microbiología Dr. Carlos Malbrán, Buenos Aires).

El diagnóstico por imágenes mediante centellograma óseo corporal total con Tc 99 reveló un aumento anormal de la concentración del trazador en el hueso ilíaco izquierdo a nivel acetabular y supra-acetabular, cuerpo vertebral D6 y región temporo-parietal derecha de la calota, sugerente de compromiso esquelético sistémico. La TAC de columna y pelvis evidenció lesiones de tipo lítico en la columna vertebral entre D7 y D12 (Figura 1), en la región ilíaca supra-acetabular izquierda y en la calota. Además en la tomografía abdominal se observaron imágenes hipodensas de contornos irregulares a nivel de hígado y bazo (Figuras 2 y 3 ).

Para descartar una histiocitosis, se realizó una biopsia de la zona de la calota comprometida, cuyo estudio anatomopatológico mostró un infiltrado mononuclear linfohistiocitario, siendo negativo para CD1A, inmunomarcador específico para histiocitosis de células de Langerhans. (Figura 4). No se observaron bacilos con la tinción de Warthin-Starry.

Con diagnóstico presuntivo de enfermedad por arañazo de gato, el paciente fue tratado con claritromicina $15 \mathrm{mg} /$ $\mathrm{kg} /$ día, durante cuatro semanas.

La evolución fue favorable con remisión completa de la sintomatología. En el seguimiento post-alta se efectuaron ecografías de control que no mostraron cambios luego de un mes de evolución.

A los cinco meses del inicio del tratamiento ya no se 


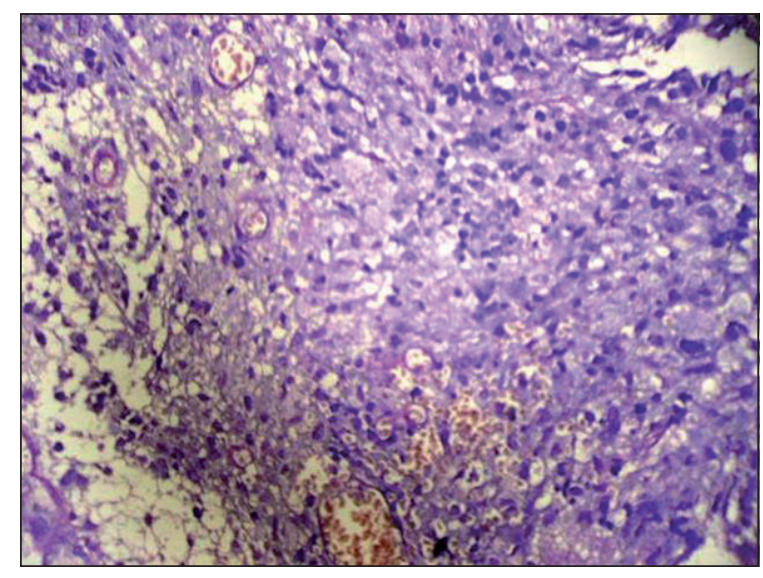

Figura 4. Estudio histopatológico de biopsia de la calota.

evidenciaron imágenes patológicas en el hígado, observándose además mejoría de las lesiones descritas en el bazo. Quedó pendiente el control centellográfico.

El progreso pondoestatural fue adecuado, permaneciendo asintomático con movilidad normal y sin dolor en todas las articulaciones.

\section{Discusión}

La enfermedad por arañazo de gato (EAG), bartonelosis, o linforreticulosis benigna de inoculación, descrita por Debré en $1950^{2}$, puede producirse por la mordedura o arañazo de gato, conejo o hurón o por lesiones con astillas de madera, espinas de pescado o de plantas contaminadas.

Se reconoce que el agente causal es $B$. henselae (ex Rochalimaea henselae), bacilo gramnegativo que se puede visualizar con la tinción argéntica de Warthin-Starry. Se han descrito dos principales genogrupos en humanos y en gatos.

Es la causa más frecuente de inflamación ganglionar crónica, de evolución generalmente autolimitada, aunque se ha descrito un amplio espectro de lesiones en todos los órganos: oculares, neurológicas, hepato-esplénicas (granulomatosis), gastrointestinales, renales, óseas, y manifestaciones hematológicas, mononucleosis pseudoinfecciosa, enfermedades pseudomalignas (histiocitosis, rabdomiosarcoma, linfoma esplénico), endocrinas y fiebre de origen desconocido. ${ }^{3}$

El caso clínico presentado se manifestó como un síndrome febril prolongado lo que obligó a descartar otros diagnósticos: osteomielitis, brucelosis, enfermedad linfoproliferativa maligna, histiocitosis de células de Langerhans y enfermedad granulomatosa crónica.

Se deben considerar los siguientes criterios diagnósticos para $\mathrm{EAG}^{4}$.
- Contacto frecuente con gatos, aun cuando el sitio de inoculación no sea visible.

- Linfoadenopatías supurativas en que se haya descartado otras etiologías: tuberculosis y otras micobacterias, hongos, enfermedad linfoproliferativa maligna (linfoma), etc.

- Aspirado ganglionar con tinción argéntica de WarthinStarry positiva, con presencia de bacilos pleomórficos e histología compatible con $B$. henselae.

- Serología positiva para $B$. henselae $(\geq 1 / 64)$.

En nuestro paciente no se obtuvo el antecedente de contacto con gatos al ingreso, sino en el transcurso de la evolución. La puerta de entrada o de inoculación puede adoptar la forma de pápula, pústula o lesión lineal o incluso pasar desapercibida, como en este caso. Al examen físico presentaba una adenopatía axilar, aunque la forma de enfermedad diseminada puede presentarse sin una linfo-adenopatía aparente.

El cuadro clínico fue compatible con EAG atípica o de forma sistémica, presentación poco frecuente, descrita en $5-10 \%$ de los casos $^{1-5}$.

Dentro del amplio espectro de manifestaciones de la forma atípica se han descrito encefalitis asociada a neumonía con efusión pleural ${ }^{6}$, casos de anemia hemolítica, adenitis mesentérica y pseudomononucleosis por $B$. henselae con serología negativa para virus de Epstein Barr, CMV, adenovirus y Toxoplasma gondii ${ }^{7}$, meningitis aséptica, neurorretinitis con pérdida aguda de la visión ${ }^{8,9}$ $\mathrm{y}$ conjuntivitis granulomatosa bilatera $\mathrm{l}^{10}$.

El compromiso hepato-esplénico con microabscesos es frecuente $(68 \%)$ y revelado por imágenes de ultrasonido ${ }^{11-13}$.

Las lesiones óseas de tipo lítico son infrecuentes, aproximadamente 1-2 por 1.000 casos descritos ${ }^{5}$. Pueden tener cualquier localización, siendo la vertebral la más común ${ }^{14,15}$. Suelen ser inaparentes en el estudio radiológico, pero pueden diagnosticarse por centellografía. A diferencia de nuestro paciente, pueden ser no dolorosas y aparecer semanas o meses después de los síntomas generales ${ }^{16}$.

La linfoadenopatía suele presentarse en un sitio alejado del hueso afectado, hecho que sugiere que la diseminación puede ser por vía hemática o linfática.

Se descartaron otras infecciones que pueden producir compromiso óseo: tuberculosis, Salmonella sp., sífilis secundaria, etc.

La presunción diagnóstica de histiocitosis de células de Langerhans se fundamentó en la existencia de lesiones osteolíticas con geodas, sin periostitis, la presencia de dolor óseo y compromiso hepato-esplénico. Sin embargo, el paciente no presentaba lesiones en la piel sugerentes de eccema seborreico ni úlceras granulomatosas en las mucosas. Su crecimiento pondoestatural era adecuado, no tenía antecedentes de compromiso pulmonar, intracraneal 
o manifestaciones asociadas como exoftalmos o diabetes insípida.

En los casos de EAG con compromiso sistémico, la serología para $B$. henselae $\operatorname{IgG}$ ha mostrado títulos mayores a 1:256 en la mayoría de las series publicadas ${ }^{17}$. La baja titulación observada en este paciente podría representar una infección antigua, con un tiempo de evolución mayor que el referido al momento de la consulta. Se considera además que títulos entre 1:64 y 1:256 podrían estar presentes en el comienzo o al final de la enfermedad y en $4-6 \%$ de las personas sanas ${ }^{17}$. No obstante, un factor importante a considerar en los puntos de corte utilizados es la seroprevalencia en la población de sujetos asintomáticos. Ésta ha resultado ser elevada en algunos estudios, siendo mayor en sujetos de áreas rurales que en áreas urbanas ${ }^{18,19}$. No poseemos datos epidemiológicos locales al respecto.

La detección de ADN por RPC obtenidos por biopsia ganglionar sería la prueba confirmatoria ideal en los casos de alta presunción y serologías negativas ${ }^{20}$.

No está demostrado que exista una correlación clínico-serológica pero sí se han descrito varios patrones serológicos: pacientes con elevación de ambas fracciones (IgM e IgG), IgM elevada sin seroconversión de IgG e $\operatorname{IgM}+\operatorname{IgG}$ en títulos bajos. La IgM negativa no excluye la infección aguda y permanece elevada aproximadamente tres meses. La IgG permanece hasta un año sólo en $25 \%$ de los $\operatorname{casos}^{21}$. La cinética temporal de la serología específica en EAG de curso subagudo es aún desconocida ${ }^{22}$, por lo que enfatizamos la importancia de la alta sospecha clínica en esta patología.

El hallazgo de $B$. henselae identificada con tinción de Warthin Starry en estudios histológicos es ocasional ${ }^{23}$. La inflamación ganglionar evoluciona en tres estadios: hipertrofia, granulomas y fusión de granulomas con necrosis central con material purulento, en el que puede visualizarse el bacilo. La tinción de Warthin-Starry en la lesión ósea puede ser negativa a los 40 días. Los focos de necrosis rodeados de elementos epitelioides en empalizada pueden verse en el tercer estadio evolutivo de las lesiones.
El CD1A en la biopsia ósea fue negativo y tampoco se observaron células gigantes con núcleos irregulares, lo que descartó el diagnóstico de histiocitosis. La evolución clínica del paciente permitió descartar además la presencia de una enfermedad linfoproliferativa maligna o proliferativa retículohistiocitaria de células de Langerhans.

La antibioterapia sería beneficiosa particularmente en los casos graves y en los niños con alteraciones inmunológicas. Se recomienda utilizar azálidas/macrólidos como azitromicina o claritromicina, o alternativas que incluyen rifampicina, ciprofloxacina, gentamicina y cotrimoxa$\mathrm{zol}^{24,25}$. Nuestro paciente recibió claritromicina durante cuatro semanas, obteniéndose una remisión rápida de los síntomas y lenta resolución de las lesiones evidenciadas ecográficamente durante meses de seguimiento. Los pacientes inmunocomprometidos deben recibir antibioterapia por seis semanas, al igual que las formas oculares y en las recaídas se recomienda prolongar la terapia hasta cuatro a seis meses.

La EAG no requiere por lo general procedimientos diagnósticos invasores; en algunos casos puede efectuarse el drenaje de las adenopatías dolorosas y fluctuantes ${ }^{26}$.

\section{Resumen}

La enfermedad por arañazo de gato (EAG) es una enfermedad infecciosa aguda usualmente benigna, relativamente común, causada por Bartonella henselae. De los casos descritos una pequeña proporción presenta compromiso extranodal. Presentamos el caso clínico de un niño de 11 años con un sindrome febril prolongado, compromiso hepático y óseo múltiple, con predominio en la columna vertebral dorsolumbar. Su evolución fue satisfactoria con resolución clínica y de las imágenes, después de varios meses de seguimiento. Se realiza una revisión de la bibliografía sobre EAG, enfatizando la necesidad de incluir esta enfermedad en el diagnóstico diferencial en pacientes con síndrome febril prolongado con compromiso óseo sugerente de una enfermedad sistémica.

\section{Referencias bibliográficas}

1.- Navarrete C M, Täger M, Wenzel M S, Podestá L L, Pincheira M, Zaror L. Formas atípicas de enfermedad por arañazo de gato, Valdivia. Rev Chilena Infectol 2003; 20: 257-61.

2.- Florin T A, Zaoutis T E, Zaoutis L B. Beyond cat-scratch disease: widening spectrum of Bartonella henselae infection. Pediatrics 2008; 121: e1413-25.

3.- Bass J W, Vincent J M, Person D A. The expanding spectrum of Bartonella infections: II. Cat-scratch disease. Pediatr Infect Dis J
1997; 16: 163-79.

4.- Carithers H A. Cat-scratch disease: an overview based on a study of 1,200 patients. Am J Dis Child 1985; 139: 1124-33.

5.- Margileth A M. Cat-scratch disease. Adv Pediatr Infect Dis 1993; 8: 1-21.

6.- Whitman B W, Krafte-Jacobs B. Cat-scratch disease associated with pleural effusions and encephalopathy in a child. Respiration 1995; 62: 171-3.

7.- Massei F, Messina F, Massimetti M, Macchia P, Maggiore G. Pseudoinfectious mononucleosis: a presentation of Bartonella henselae infection. Arch Dis Child 2000; 83: 443-4.
8.- Pinto V L, Curi A L, Pinto Ada S, Nunes E P, Teixeira M de L, Rozental T, et al. Cat scratch-disease complicated with aseptic meningitis and neuroretinitis. Braz J Infect Dis 2008; 12: 158-60.

9.- Täger F M, Jahnsen K J, Mediavilla R M, Burgos L R. Bartonelosis ocular: reporte de 3 casos. Rev Chilena Infectol 2008; 25: 58-63.

10.- Príncipe de Oliveira A H, Pires Pereira C A, Barbosa de Sousa L, De Freitas D. Conjuntivite granulomatosa atípica causada pela doenca da arranhadura do gato. Relato de caso. Arq Bras Oftalmol 2004; 67: 541-3.

11.- Arisoy E S, Correa A G, Wagner M L, 
Kaplan S L. Hepatoesplenic cat-scratch disease in children: selected clinical features and treatment. Clin Infect Dis 1999; 28: 778-84.

12.- Massei F, Massimetti F, Messina F, Macchia P, Maggiore G. Bartonella henselae and inflammatory bowel disease. Lancet 2000; 356: $1245-6$

13.- Medici Olaso C, García Gariglio L, Ferreira García M I, Giachetto Larraz G, Gutiérrez Bottino M C, Pires García M C. Enfermedad por arañazo de gato: características clínicas en niños hospitalizados. An Pediatr (Barc) 2011; 74: 42-6.

14.- Hulzebos C V, Koetse H A, Kimpen J L, Wolfs T F. Vertebral osteomyelitis associated with cat- scratch disease. Clin Infect Dis 1999; 28: 1310-2.

15.- Wolff P E, Muñoz F M, Zapata F C, Ledermann D W. Enfermedad por arañazo de gato complicada con compromiso sistémico, osteomielitis osteovertebral y absceso paravertebral. Rev Chilena Infectol 2000; 17: 332-9.

16.- Ladrón de Guevara H D, Lobo S G, Miranda A M, Wu H E, Muñoz G M A, Pérez R A, et al. Forma atípica de enfermedad por arañazo de gato: compromiso óseo en dos pacientes pediátricos detectado mediante cintigrafía ósea. Rev Chilena Infectol 2003; 20: 202-9

17.- Eymin G, Zapata A, Andrade M, Aizman A, Rojas L, Rabagliati R. Enfermedad por arañazo de gato. Características clínicas y de laboratorio en ocho pacientes adultos hospitalizados por fiebre o adenopatías. Rev Med Chile 2006; 134 : 1243-8.

18.- Zangwill K M, Hamilton D H, Perkins B A, Regnery R L, Plikaytis B D, Hadler J L, et al. Cat-scratch disease in Connecticut. Epidemiology, risk factors, and evaluation of a new diagnostic test. N Engl J Med 1993; 329: 8-13.

19.- Massei F, Messina F, Gori L, Macchia P, Maggiore G. High prevalence of antibodies to Bartonella henselae among italian children without evidence of cat-scratch disease. Clin Infect Dis 2004; 38: 145-8.

20.- Chondrogiannis K, Vezakis A, Derpapas M, Melemeni A, Fragulidis G. Seronegative cat scratch-disease diagnosed by PCR detection of Bartonella henselae DNA in lymph node samples. Braz J Infect Dis 2012; 16: 96-9.

21.- Metzcor-Cotter E, Kletter Y, Avidor B,
Varon M, Golan Y, Ephros M, et al. Long-term serological analysis and clinical follow-up of patients with cat-scratch disease. Clin Infect Dis 2003; 37: 1149-54.

22.- Nadal D, Zbinden R. Serology to Bartonella (Rochalimaea) henselae may replace traditional diagnostic criteria for cat-scratch disease. Eur J Pediatr 1995; 154: 906-8.

23.- Manfredi R, Sabbatani S. Bartonellosis: suggestive case reports in adult and pediatric patients and therapeutic issues. Braz J Infect Dis 2006; 10: 411-5.

24.- Huarcaya E, Maguiña C, Merello J, Cok J, Birtles R, Infante B, et al. A prospective study of cat-scratch disease in Lima, Perú. Rev Inst Med Trop Sao Paulo 2002; 44: 325-30.

25.- Aragao R E, Ramos R M, Bezerra A F, Cavalcanti Júnior R B, Alburquerque T L. Optic neuropathy secondary to cat scratch disease: case report. Arq Bras Oftalmol 2010; 73: $537-8$.

26.- Schutze G E, Jacobs R F. Chapter 160: Bartonella species (Cat-scratch disease). En Long S, Pickering L, Prober C. eds. Principles and Practice of Pediatric Infectious Diseases. 3rd edition. Churchill Livingstone Elsevier, Philadelphia 2008; 851-5. 